\title{
Selective loading of platinum cocatalyst onto zinc rhodium oxide in a silver-inserted heterojunction overall water-splitting photocatalyst consisting of zinc rhodium oxide and bismuth vanadium oxide
}

\author{
Hiroshi IRIE ${ }^{1,2, \dagger}$, Masaomi YODA ${ }^{2}$, Toshihiro TAKASHIMA ${ }^{1,2}$ and Junya OSAKI ${ }^{2}$ \\ ${ }^{1}$ Clean Energy Research Center, University of Yamanashi, 4-3-11 Takeda, Kofu, Yamanashi 400-8511, Japan \\ ${ }^{2}$ Special Educational Program for Green Energy Conversion Science and Technology, Integrated Graduate School of Medicine, \\ Engineering, and Agricultural Sciences, University of Yamanashi, 4-3-11 Takeda, Kofu, Yamanashi 400-8511, Japan
}

\begin{abstract}
Platinum (Pt) was selectively photodeposited onto zinc rhodium oxide $\left(\mathrm{ZnRh}_{2} \mathrm{O}_{4}\right)$ to serve as a hydrogen $\left(\mathrm{H}_{2}\right)$ evolution photocatalyst in a silver (Ag)-inserted $\mathrm{ZnRh}_{2} \mathrm{O}_{4}$ and bismuth vanadium oxide $\left(\mathrm{Bi}_{4} \mathrm{~V}_{2} \mathrm{O}_{11}\right)$ solid-state photocatalyst $\left(\mathrm{ZnRh}_{2} \mathrm{O}_{4} / \mathrm{Ag} / \mathrm{Bi}_{4} \mathrm{~V}_{2} \mathrm{O}_{11}\right)$. The amount of deposited Pt was controlled by the photodeposition time to generate Pt-loaded $\mathrm{ZnRh}_{2} \mathrm{O}_{4} / \mathrm{Ag} / \mathrm{Bi}_{4} \mathrm{~V}_{2} \mathrm{O}_{11}\left(\mathrm{Pt} / \mathrm{ZnRh} \mathrm{O}_{4} / \mathrm{Ag} / \mathrm{Bi}_{4} \mathrm{~V}_{2} \mathrm{O}_{11}\right)$ containing up to $0.17 \mathrm{wt} \%$ of $\mathrm{Pt}$ cocatalyst. The prepared $\mathrm{Pt} / \mathrm{ZnRh} \mathrm{O}_{4} / \mathrm{Ag} / \mathrm{Bi}_{4} \mathrm{~V}_{2} \mathrm{O}_{11}$ photocatalysts were able to catalyze the overall pure-water splitting reaction under irradiation with red light at a wavelength of $700 \mathrm{~nm}$ and enhanced the stoichiometric evolution of $\mathrm{H}_{2}$ and $\mathrm{O}_{2}$ from water at $\mathrm{Pt}$ amounts exceeding $0.12 \mathrm{wt} \%$ of Pt. The apparent quantum efficiency of the water-splitting reaction was highest at $0.17 \mathrm{wt} \%$ of Pt. In addition to the loading amount of Pt, the loading of $\mathrm{Pt}$ as $\mathrm{Pt}^{0}$ (metallic Pt) is crucial for enhancing the water-splitting activity of $\mathrm{Pt} / \mathrm{ZnRh}_{2} \mathrm{O}_{4} / \mathrm{Ag} / \mathrm{Bi}_{4} \mathrm{~V}_{2} \mathrm{O}_{11}$. (02021 The Ceramic Society of Japan. All rights reserved.
\end{abstract}

Key-words : Overall pure water-splitting, Platinum, Cocatalyst, Two-step photoexcitation

[Received December 22, 2020; Accepted April 15, 2021]

\section{Introduction}

Several photocatalysts and photocatalytic systems aimed at water splitting have been investigated ${ }^{1)}$ because the generated hydrogen $\left(\mathrm{H}_{2}\right)$ gas is a versatile and clean energy carrier. Since the first report of overall water splitting at wavelengths up to $\sim 480 \mathrm{~nm}$ over a solid solution of gallium nitride-zinc oxide and a mixed oxide of rhodium and chromium as a cocatalyst, ${ }^{2)}$ most research on powdered photocatalysts has focused on increasing the sensitivity of these one-step systems to longer wavelengths of visible light to allow the more efficient utilization of solar energy. Recently, a yttrium titanium oxysulfide $\left.\left(\mathrm{Y}_{2} \mathrm{Ti}_{2} \mathrm{O}_{5} \mathrm{~S}_{2}\right)^{3}\right)$ was demonstrated to be capable of overall water splitting under irradiation at $\sim 630 \mathrm{~nm}$, which is the longest wavelength reported to date for a one-step photoexcitation system.

As an alternative to one-step photoexcitation systems, two-step systems, which combine $\mathrm{H}_{2}$-evolution photocatalyst $\left(\mathrm{H}_{2}\right.$ photocatalyst $)$ and $\mathrm{O}_{2}$-evolution photocatalyst $\left(\mathrm{O}_{2}\right.$ photocatalyst), are also able to split water under visible-light irradiation. ${ }^{4)}$ However, because such two-step systems, which are termed "Z-scheme", require the presence of a suitable redox mediator, such as iodate ion

Corresponding author: H. Irie; E-mail: hirie@yamanashi. ac.jp
$\left(\mathrm{IO}_{3}{ }^{-}\right)$/iodide ion $\left(\mathrm{I}^{-}\right)$or ferric ion $\left(\mathrm{Fe}^{3+}\right) /$ ferrous ion $\left(\mathrm{Fe}^{2+}\right)$, these systems are not able to split pure water.

To achieve overall pure-water splitting under irradiation with visible light, we developed two-step solid-state Zscheme photocatalysts by inserting either silver $(\mathrm{Ag})$ or gold $(\mathrm{Au})$ as an electron mediator between zinc rhodium oxide $\left(\mathrm{ZnRh}_{2} \mathrm{O}_{4}\right.$, bandgap $\left(E_{\mathrm{g}}\right)$ of $\left.1.2 \mathrm{eV}\right)$ as the $\mathrm{H}_{2}$ photocatalyst and bismuth vanadate $\left(\mathrm{Bi}_{4} \mathrm{~V}_{2} \mathrm{O}_{11}, E_{\mathrm{g}}\right.$ of $\left.1.7 \mathrm{eV}\right)$ as the $\mathrm{O}_{2}$ photocatalyst. ${ }^{5)-8)}$ In these systems, which were designated $\mathrm{ZnRh}_{2} \mathrm{O}_{4} / \mathrm{Ag} / \mathrm{Bi}_{4} \mathrm{~V}_{2} \mathrm{O}_{11}$ and $\mathrm{ZnRh}_{2} \mathrm{O}_{4} / \mathrm{Au} /$ $\mathrm{Bi}_{4} \mathrm{~V}_{2} \mathrm{O}_{11}$, overall pure-water splitting proceeded via $\mathrm{Ag}$ or $\mathrm{Au}$, which mediated the transfer of photoexcited electrons from the conduction band of $\mathrm{Bi}_{4} \mathrm{~V}_{2} \mathrm{O}_{11}$ to the valence band of $\mathrm{ZnRh}_{2} \mathrm{O}_{4}$. These photocatalysts were capable of utilizing visible light at wavelengths up to $740 \mathrm{~nm}$, which represents nearly the entire visible light spectrum and to our knowledge, is the longest wavelength reported to date. Several recent studies have described similar heterojunction photocatalysts, demonstrating the potential of these systems for overall water splitting. ${ }^{9)-13)}$

In our previous work, the selective photodeposition of $\mathrm{Ag}$ or platinum $(\mathrm{Pt})$ as $\mathrm{H}_{2}$-favorable cocatalysts onto $\mathrm{ZnRh}_{2} \mathrm{O}_{4}$ in $\mathrm{ZnRh}_{2} \mathrm{O}_{4} / \mathrm{Ag} / \mathrm{Bi}_{4} \mathrm{~V}_{2} \mathrm{O}_{11}$ resulted in enhanced stoichiometric $\mathrm{H}_{2}$ and $\mathrm{O}_{2}$ evolution from pure water. ${ }^{14), 15)}$ Here, we evaluated the dependence of the apparent quantum efficiency (AQE) of the overall water splitting activity on the amount and valency of Pt. 


\section{Experimental section}

\subsection{Sample preparation}

$\mathrm{ZnRh}_{2} \mathrm{O}_{4}$ and $\mathrm{Bi}_{4} \mathrm{~V}_{2} \mathrm{O}_{11}$ powders were synthesized by a solid-state reaction method. As starting materials, $\mathrm{ZnO}$ (Wako, purity $99.0 \%$ ) and $\mathrm{Rh}_{2} \mathrm{O}_{3}$ powders (Kanto Kagaku, purity $99.9 \%$ ) were used to synthesize $\mathrm{ZnRh}_{2} \mathrm{O}_{4}$, and $\mathrm{Bi}_{2} \mathrm{O}_{3}$ (Kanto Kagaku, purity $99.9 \%$ ) and $\mathrm{V}_{2} \mathrm{O}_{5}$ powders (Kanto Kagaku, purity $99.0 \%$ ) were used to synthesize $\mathrm{Bi}_{4} \mathrm{~V}_{2} \mathrm{O}_{11}$. Stoichiometric amounts of both pairs of starting materials were thoroughly mixed, and the resulting mixtures were calcined in air at $1150{ }^{\circ} \mathrm{C}$ for $24 \mathrm{~h}$ and $850^{\circ} \mathrm{C}$ for $8 \mathrm{~h}$ to obtain $\mathrm{ZnRh}_{2} \mathrm{O}_{4}$ and $\mathrm{Bi}_{4} \mathrm{~V}_{2} \mathrm{O}_{11}$ powders, respectively. The $\mathrm{Bi}_{4} \mathrm{~V}_{2} \mathrm{O}_{11}$ powder was subsequently soaked in distilled water for $20 \mathrm{~h}$ with constant stirring, followed by filtration and drying at $65^{\circ} \mathrm{C}$ for $12 \mathrm{~h} .{ }^{15}$ )

The prepared $\mathrm{ZnRh}_{2} \mathrm{O}_{4}$ and $\mathrm{Bi}_{4} \mathrm{~V}_{2} \mathrm{O}_{11}$ powders, and $\mathrm{Ag}_{2} \mathrm{O}$ (Kanto Kagaku, purity $99.0 \%$ ) powder were thoroughly mixed at a molar ratio of 1.0:1.2:1.0 and were then pressed into pellets of $12 \mathrm{~mm}$ in diameter by applying a force of $60 \mathrm{kN}$. The obtained pellets were heated in air at $750^{\circ} \mathrm{C}$ for $2 \mathrm{~h}$ and were then ground into a fine powder, which was soaked in a $3 \mathrm{M}$ nitric acid $\left(\mathrm{HNO}_{3}\right.$, Kanto $\mathrm{Kagaku}$ ) aqueous solution for $5 \mathrm{~min}$. The powder was then filtered, washed thoroughly with distilled water, and dried at $65^{\circ} \mathrm{C}$ for $12 \mathrm{~h}$.

Photodeposition of $\mathrm{Pt}$ was conducted by dispersing 80 $\mathrm{mg} \mathrm{ZnRh}_{2} \mathrm{O}_{4} / \mathrm{Ag} / \mathrm{Bi}_{4} \mathrm{~V}_{2} \mathrm{O}_{11}$ in $40 \mathrm{~mL}$ formaldehyde solution (HCHO, $25 \mathrm{vol} \%$ ) containing $10 \mathrm{~mL}$ of $8.65 \mathrm{mM}$ hexachloroplatinic acid $\left(\mathrm{H}_{2} \mathrm{PtCl}_{6} \cdot 6 \mathrm{H}_{2} \mathrm{O},>98.5 \%\right.$; Kanto Kagaku) as the Pt source. The resulting suspension was deaerated using liquid nitrogen and illuminated by a lightemitting diode (LED) lamp with a wavelength of $850 \mathrm{~nm}$ (LEDH60-850; Hamamatsu Photonics) and equipped with an optical filter (IR85N; HOYA) for 4, 20, 35, and $50 \mathrm{~h}$ under constant stirring. This light condition was used for the selective photo-excitation of $\mathrm{ZnRh}_{2} \mathrm{O}_{4}$, which has an $E_{\mathrm{g}}$ that is $0.5 \mathrm{eV}$ lower than that of $\mathrm{Bi}_{4} \mathrm{~V}_{2} \mathrm{O}_{11}$ (1.2 vs. 1.7 $\mathrm{eV}$, respectively). The resulting sample was obtained by filtration, washed, and dried at $80^{\circ} \mathrm{C}$ overnight.

\subsection{Characterizations}

The crystal structures of the prepared powders were determined by X-ray diffraction (XRD) using a PW-1700 instrument (PANalytical). Ultraviolet-visible absorption (UV-vis) spectra were obtained by the diffuse reflection method using a spectrometer (V-650, Jasco) with barium sulfate $\left(\mathrm{BaSO}_{4}\right)$ as the reflectance standard. The amounts of photodeposited Pt was evaluated by inductively coupled plasma optical emission spectrometry (ICP-OES, SPS3500 DD, Hitachi). The Bi 4f, V 2p, Zn 2p, Rh 3d, Ag 3d, and $\mathrm{Pt} 4 \mathrm{f}$ core levels were measured by X-ray photoelectron spectroscopy (XPS; Axis-Ultra, Shimadzu). The XPS peaks were calibrated using the $\mathrm{C} 1 \mathrm{~s}$ peak derived from a hydrocarbon surface contaminant with a binding energy of $284.5 \mathrm{eV}$. To quantitatively evaluate the valencies of $\mathrm{Ag}$ and $\mathrm{Pt}$ contained in the photocatalyst, peak deconvolution was performed using a Gaussian lineshape.

\subsection{Photocatalytic water splitting tests}

Photocatalytic overall water splitting tests were performed in a gas-closed circulation system. The composite photocatalysts $(60 \mathrm{mg})$ were suspended in $12 \mathrm{~mL}$ pure water (distilled water, $\mathrm{pH}$ unadjusted) under constant magnetic stirring in an argon atmosphere $(50 \mathrm{kPa})$ after repeated evacuation until reaching $2.5 \mathrm{~Pa}$. An LED lamp with a wavelength of $700 \mathrm{~nm}$ (LEDH60-700, Hamamatsu Photonics) was used for light irradiation. The amounts of evolved $\mathrm{H}_{2}$ and $\mathrm{O}_{2}$ were monitored using an online gas chromatograph (GC-8A, Shimadzu).

AQE was calculated using the amount of evolved $\mathrm{H}_{2}$ and the equation $\mathrm{AQE}(\%)=100 \times 4 \times \mathrm{H}_{2}$ generation rate/incident photon rate, because $\mathrm{H}_{2}$ generation in twostep systems is a four-electron process. ${ }^{16)}$

\section{Results and discussion}

\subsection{Characterization}

The XRD patterns of $\mathrm{Pt} / \mathrm{ZnRh}_{2} \mathrm{O}_{4} / \mathrm{Ag} / \mathrm{Bi}_{4} \mathrm{~V}_{2} \mathrm{O}_{11}$ after $35 \mathrm{~h}$ of $\mathrm{Pt}$ photodeposition as a representative and bare $\mathrm{ZnRh}_{2} \mathrm{O}_{4} / \mathrm{Ag} / \mathrm{Bi}_{4} \mathrm{~V}_{2} \mathrm{O}_{11}$ were first compared (Fig. 1). The XRD peaks of both samples appeared similar and mainly corresponded to $\mathrm{ZnRh}_{2} \mathrm{O}_{4}$ and $\mathrm{Bi}_{4} \mathrm{~V}_{2} \mathrm{O}_{11}$, with the trace peaks being ascribed to an unknown $\mathrm{Ag}$ oxide (likely $\mathrm{AgVO}_{3}$ ). Other photodeposited photocatalysts indicated the similar XRD patterns. Notably, peaks corresponding to $\mathrm{Ag}$ and Pt peaks were not observed, indicating that the amounts of residual $\mathrm{Ag}$ and photodeposited Pt were too low for detection. These observations are consistent with those reported previously. ${ }^{14)}$ The XPS results demonstrated that $\mathrm{Ag}$ existed as $\mathrm{Ag}^{0}$ (metallic $\mathrm{Ag}$ ) and $\mathrm{Pt}$ as $\mathrm{Pt}^{0}, \mathrm{Pt}^{2+}$, and $\mathrm{Pt}^{3+}$. The implications of these findings are discussed below.

The UV-vis diffuse reflection spectra of bare $\mathrm{ZnRh}_{2} \mathrm{O}_{4} /$ $\mathrm{Ag} / \mathrm{Bi}_{4} \mathrm{~V}_{2} \mathrm{O}_{11}$ and $\mathrm{Pt} / \mathrm{ZnRh}_{2} \mathrm{O}_{4} / \mathrm{Ag} / \mathrm{Bi}_{4} \mathrm{~V}_{2} \mathrm{O}_{11}$ (35-h photodeposition) were next examined (Fig. 2). The Pt $/ \mathrm{ZnRh}_{2} \mathrm{O}_{4} /$ $\mathrm{Ag} / \mathrm{Bi}_{4} \mathrm{~V}_{2} \mathrm{O}_{11}$ spectrum had greater 100-reflectance than that of bare $\mathrm{ZnRh}_{2} \mathrm{O}_{4} / \mathrm{Ag} / \mathrm{Bi}_{4} \mathrm{~V}_{2} \mathrm{O}_{11}$ in the longer wavelength region, a property that is attributable to the photodeposited Pt.

Elemental analysis by ICP-OES indicated that the Pt amounts were $0.10,0.12,0.17$, and $0.14 \mathrm{wt} \%$ containing

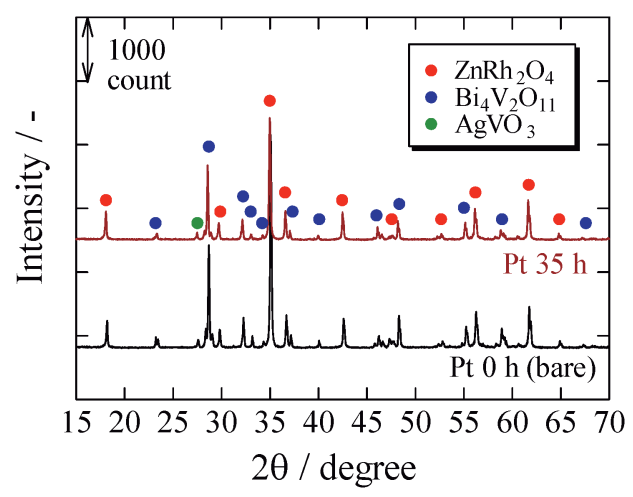

Fig. 1. Powder XRD patterns of $\mathrm{Pt} / \mathrm{ZnRh}{ }_{2} \mathrm{O}_{4} / \mathrm{Ag} / \mathrm{Bi}_{4} \mathrm{~V}_{2} \mathrm{O}_{11}$ after $35 \mathrm{~h}$ of $\mathrm{Pt}$ photodeposition and bare $\mathrm{ZnRh}_{2} \mathrm{O}_{4} / \mathrm{Ag} /$ $\mathrm{Bi}_{4} \mathrm{~V}_{2} \mathrm{O}_{11}$ 
in the photocatalysts with Pt photodeposition times of 4 , 20, 35, and $50 \mathrm{~h}$, respectively (Table 1). The amount of deposited $\mathrm{Pt}$ increased to $0.17 \mathrm{wt} \%$ with increasing photodeposition time up to $35 \mathrm{~h}$, but then decreased. As a possible reason for this result, increasing the amount of $\mathrm{Pt}$ on $\mathrm{ZnRh}_{2} \mathrm{O}_{4}$ may have caused a light shading effect, preventing $\mathrm{ZnRh}_{2} \mathrm{O}_{4}$ from being photoexcited and/or in-

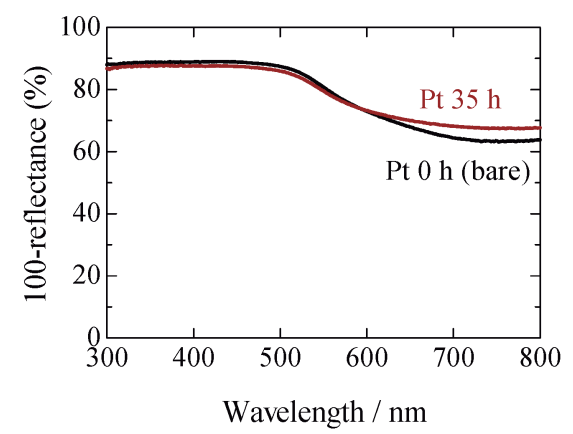

Fig. 2. UV-vis diffuse reflection spectra of $\mathrm{Pt} / \mathrm{ZnRh}_{2} \mathrm{O}_{4} / \mathrm{Ag} /$ $\mathrm{Bi}_{4} \mathrm{~V}_{2} \mathrm{O}_{11}$ after $35 \mathrm{~h}$ of $\mathrm{Pt}$ photodeposition and bare $\mathrm{ZnRh}_{2} \mathrm{O}_{4}$ / $\mathrm{Ag} / \mathrm{Bi}_{4} \mathrm{~V}_{2} \mathrm{O}_{11}$.

Table 1. Pt weight percentage in $\mathrm{Pt} / \mathrm{ZnRh}_{2} \mathrm{O}_{4} / \mathrm{Ag} / \mathrm{Bi}_{4} \mathrm{~V}_{2} \mathrm{O}_{11}$ and percentages of $\mathrm{Pt}^{0}, \mathrm{Pt}^{2+}$, and $\mathrm{Pt}^{3+}$ including in the photodeposited $\mathrm{Pt}$

\begin{tabular}{ccccr}
\hline $\begin{array}{c}\text { Photodeposition } \\
\text { time } / \mathrm{h}\end{array}$ & $\mathrm{Pt} / \mathrm{wt} \% * 1)$ & $\mathrm{Pt}^{0} / \%^{* 2)}$ & $\mathrm{Pt}^{2+} / \%^{* 2)}$ & $\mathrm{Pt}^{3+} / \%^{* 2)}$ \\
\hline 4 & 0.10 & $36 \pm 8$ & $57 \pm 2$ & $8 \pm 6$ \\
20 & 0.12 & $43 \pm 2$ & $42 \pm 3$ & $16 \pm 5$ \\
35 & 0.17 & $62 \pm 2$ & $27 \pm 2$ & $12 \pm 1$ \\
50 & 0.14 & $61 \pm 1$ & $32 \pm 0$ & $7 \pm 1$ \\
\hline
\end{tabular}

*1) Obtained by ICP-OES.

${ }^{* 2)}$ Average values of the two times $\mathrm{Pt} 4 \mathrm{f}$ measurements for each $\mathrm{Pt} /$ $\mathrm{ZnRh}_{2} \mathrm{O}_{4} / \mathrm{Ag} / \mathrm{Bi}_{4} \mathrm{~V}_{2} \mathrm{O}_{11}$ and their peak deconvolution. Figures 3(g)-3(j) are one of the series of $\mathrm{Pt} 4 \mathrm{f}$ data and their deconvolution results out of two measurements. Value obtained using: $100 \times \mathrm{Pt}^{0} /\left(\mathrm{Pt}^{0}+\mathrm{Pt}^{2+}+\mathrm{Pt}^{3+}\right)$, $100 \times \mathrm{Pt}^{2+} /\left(\mathrm{Pt}^{0}+\mathrm{Pt}^{2+}+\mathrm{Pt}^{3+}\right), 100 \times \mathrm{Pt}^{3+} /\left(\mathrm{Pt}^{0}+\mathrm{Pt}^{2+}+\mathrm{Pt}^{3+}\right)$. creasing Pt detachment at a rate that exceeded Pt deposition. To determine the valency of $\mathrm{Ag}$ and $\mathrm{Pt}$ in the prepared photocatalysts, a peak deconvolution method was applied to the $\mathrm{Ag} 3 \mathrm{~d}$ and $\mathrm{Pt} 4 \mathrm{f}$ peaks (Fig. 3). In Figs. 3(a)-3(e), all of the photocatalysts were deconvoluted by one pair of $\mathrm{Ag} 3 \mathrm{~d}$ peaks by fixing the $\mathrm{Ag} 3 \mathrm{~d}_{5 / 2}$ and $\mathrm{Ag} 3 \mathrm{~d}_{3 / 2}$ peaks, which are attributable to metallic $\mathrm{Ag}$ $\left(\mathrm{Ag}^{0}\right)$ and had binding energies of $368.6 \pm 0.1$ and $374.6 \pm 0.1 \mathrm{eV}$, respectively, and by fixing the peak area ratio of $\mathrm{Ag} 3 \mathrm{~d}_{5 / 2}$ to $\mathrm{Ag} 3 \mathrm{~d}_{3 / 2}$ at $0.667 .{ }^{14), 17), 18)}$ These results indicate that $\mathrm{Ag}$ exists as metallic particles when inserted between $\mathrm{ZnRh}_{2} \mathrm{O}_{4}$ and $\mathrm{Bi}_{4} \mathrm{~V}_{2} \mathrm{O}_{11}$ in $\mathrm{ZnRh}_{2} \mathrm{O}_{4} / \mathrm{Ag} /$ $\mathrm{Bi}_{4} \mathrm{~V}_{2} \mathrm{O}_{11}$ and $\mathrm{Pt} / \mathrm{ZnRh}_{2} \mathrm{O}_{4} / \mathrm{Ag} / \mathrm{Bi}_{4} \mathrm{~V}_{2} \mathrm{O}_{11}$. In contrast, the $\mathrm{Pt} 4 \mathrm{f}$ peaks were deconvoluted by three pairs of $\mathrm{Pt} 4 \mathrm{f}$ peaks with binding energies of $71.1 \pm 0.2 \mathrm{eV}\left(\mathrm{Pt}_{4 / 2}\right)$ and $74.6 \pm 0.2 \mathrm{eV}\left(\mathrm{Pt} \mathrm{4f_{5/2 }}\right)$ for metallic $\mathrm{Pt}\left(\mathrm{Pt}^{0}\right), 72.1 \pm$ $0.2 \mathrm{eV}\left(\mathrm{Pt}_{4 / 2}\right)$ and $75.6 \pm 0.2 \mathrm{eV}\left(\mathrm{Pt}_{4 / 2}\right)$ for $\mathrm{Pt}^{2+}$, and $73.1 \pm 0.2 \mathrm{eV}\left(\mathrm{Pt} 4 \mathrm{f}_{7 / 2}\right)$ and $76.6 \pm 0.2 \mathrm{eV}\left(\mathrm{Pt}_{4} \mathrm{f}_{5 / 2}\right)$ for $\mathrm{Pt}^{3+}$ [Figs. 3(g)-3(j)]. ${ }^{14), 19)}$ The peak area ratio of $\mathrm{Pt} 4 \mathrm{f}_{5 / 2}$ to $\mathrm{Pt} 4 \mathrm{f}_{7 / 2}$ for $\mathrm{Pt}^{0}, \mathrm{Pt}^{2+}$, and $\mathrm{Pt}^{3+}$ was fixed at 0.75 . The total $\mathrm{Pt}^{0}, \mathrm{Pt}^{2+}$, and $\mathrm{Pt}^{3+}$ areas were determined by summing the corresponding deconvolution areas of $\mathrm{Pt} 4 \mathrm{f}_{5 / 2}$ and $\mathrm{Pt} 4 \mathrm{f}_{7 / 2}$, and the atomic ratios of $\mathrm{Pt}^{0}, \mathrm{Pt}^{2+}$, and $\mathrm{Pt}^{3+}$ vs. total Pt were then calculated (Table 1). Thus, although the major Pt species that functioned as the cocatalyst was $\mathrm{Pt}^{0}$, $\mathrm{Pt}^{4+}$ was not fully reduced to $\mathrm{Pt}^{0}$.

We previously demonstrated by elemental mapping using scanning transmission electron microscopy and energy-dispersive $\mathrm{X}$-ray spectrometry that $\mathrm{Pt}$ is specifically photodeposited onto $\left.\mathrm{ZnRh}_{2} \mathrm{O}_{4}{ }^{14}\right)$ Thus, we consider that the $\mathrm{Bi}_{4} \mathrm{~V}_{2} \mathrm{O}_{11}$ surface remains unaltered even after the deposition of the cocatalyst. The XPS peaks V 2 $p_{3 / 2}$, $\mathrm{Zn} \mathrm{2p}$, and $\mathrm{Rh} 3 \mathrm{~d}$ were normalized for all of photocatalysts using the peak areas of Bi 4f [Figs. 4(a)-4(d)]. The peak areas in the normalized $\mathrm{V} 2 \mathrm{p}_{3 / 2}$ spectra were reasonably similar among all of the photocatalysts

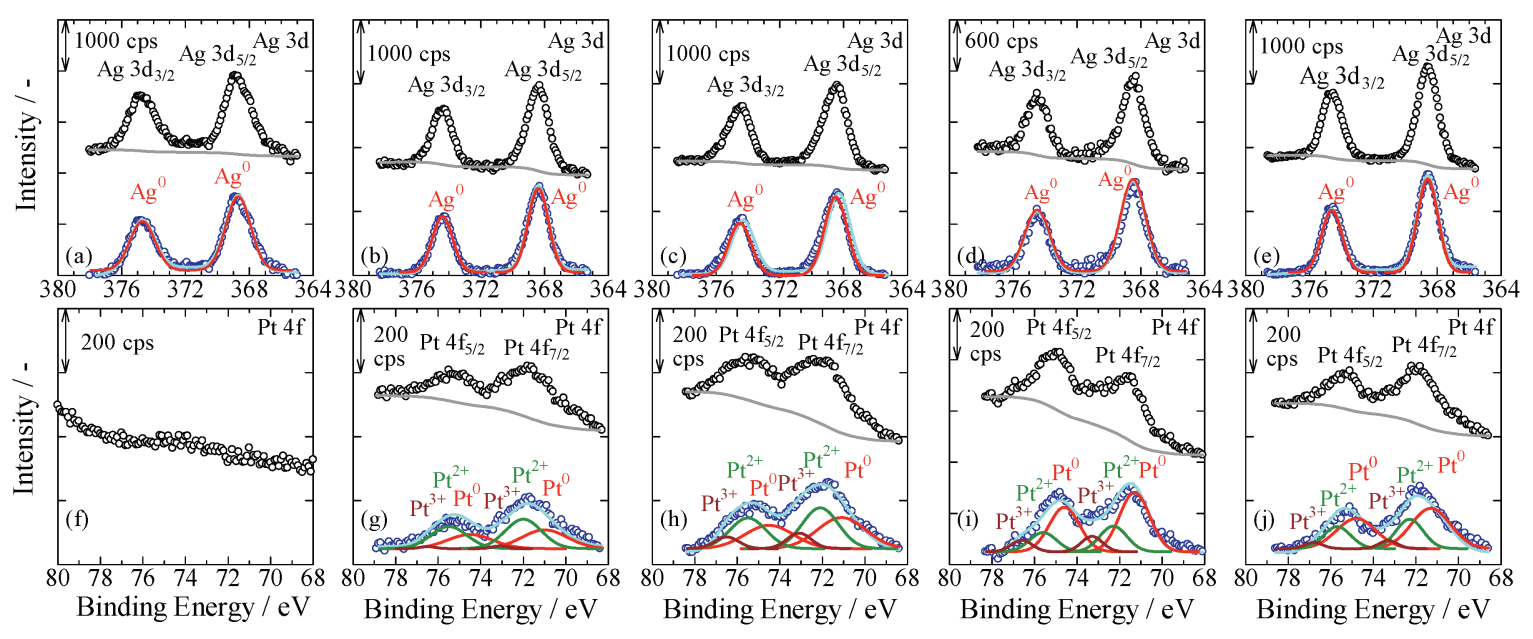

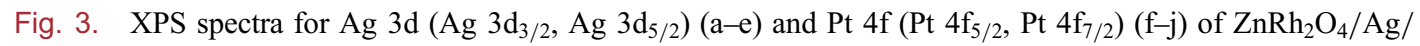
$\mathrm{Bi}_{4} \mathrm{~V}_{2} \mathrm{O}_{11}$ (a, f), and $\mathrm{Pt} / \mathrm{ZnRh}_{2} \mathrm{O}_{4} / \mathrm{Ag} / \mathrm{Bi}_{4} \mathrm{~V}_{2} \mathrm{O}_{11}$ prepared with $\mathrm{Pt}$ photodeposition times of $4 \mathrm{~h}(\mathrm{~b}, \mathrm{~g}), 20 \mathrm{~h}$ $(\mathrm{c}, \mathrm{h}), 35 \mathrm{~h}(\mathrm{~d}, \mathrm{i})$, and $50 \mathrm{~h}(\mathrm{e}, \mathrm{j})$. The blue open circles in the lower part of each plot were generated by subtracting the background (gray line, upper) from the experimental XPS data (black open plots, upper). The blue open plots closely coincided with the fitted curves (light blue lines, which represent the sum of the contributions obtained by deconvolution (red, green, and brown lines). 


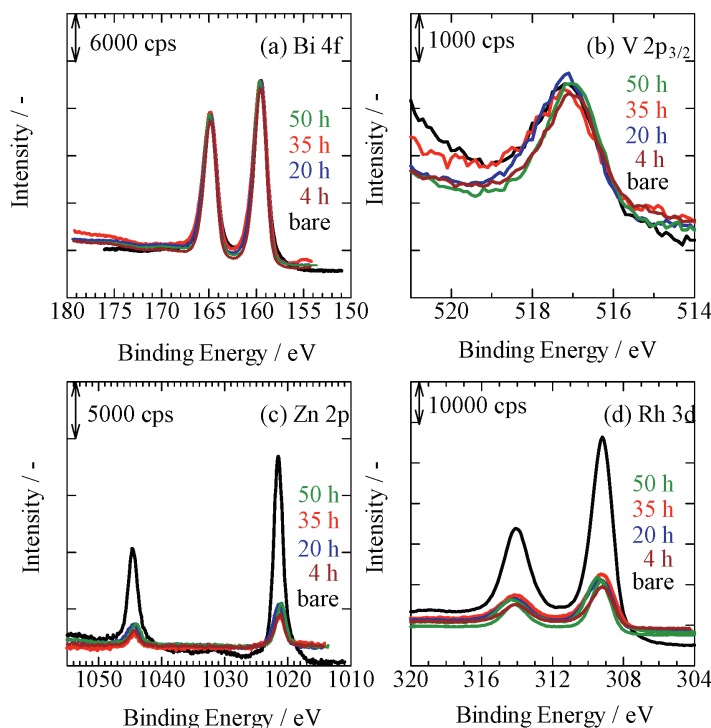

Fig. 4. Normalized XPS spectra of bare $\mathrm{ZnRh}_{2} \mathrm{O}_{4} / \mathrm{Ag} /$ $\mathrm{Bi}_{4} \mathrm{~V}_{2} \mathrm{O}_{11}$ (black lines) and $\mathrm{Pt} / \mathrm{ZnRh}_{2} \mathrm{O}_{4} / \mathrm{Ag} / \mathrm{Bi}_{4} \mathrm{~V}_{2} \mathrm{O}_{11}$ prepared by photodeposition for $4 \mathrm{~h}$ (brown lines), $20 \mathrm{~h}$ (blue lines), $35 \mathrm{~h}$ (red lines), and $50 \mathrm{~h}$ (green lines) for Bi $4 \mathrm{f}(\mathrm{a}), \mathrm{V} 2 \mathrm{p} \mathrm{(b),} \mathrm{Zn} 2 \mathrm{p}$ (c), and Rh 3d (d).

[Fig. 4(b)]. In addition, the normalized $\mathrm{Zn} 2 \mathrm{p}$ and $\mathrm{Rh} 3 \mathrm{~d}$ peaks of $\mathrm{Pt} / \mathrm{ZnRh}_{2} \mathrm{O}_{4} / \mathrm{Ag} / \mathrm{Bi}_{4} \mathrm{~V}_{2} \mathrm{O}_{11}$ were smaller than those of $\mathrm{ZnRh}_{2} \mathrm{O}_{4} / \mathrm{Ag} / \mathrm{Bi}_{4} \mathrm{~V}_{2} \mathrm{O}_{11}$ [Figs. 4(c) and 4(d)]. These surface-sensitive XPS results are consistent with the speculation that $\mathrm{Pt}$ was selectively deposited onto $\mathrm{ZnRh}_{2} \mathrm{O}_{4}$.

\subsection{Photocatalytic water splitting tests}

The time courses of $\mathrm{H}_{2}$ and $\mathrm{O}_{2}$ evolution from $\mathrm{Pt} /$ $\mathrm{ZnRh}_{2} \mathrm{O}_{4} / \mathrm{Ag} / \mathrm{Bi}_{4} \mathrm{~V}_{2} \mathrm{O}_{11}$ after Pt photodeposition for 4, 20, 35 , and $50 \mathrm{~h}$ were compared with bare $\mathrm{ZnRh}_{2} \mathrm{O}_{4} / \mathrm{Ag} /$ $\mathrm{Bi}_{4} \mathrm{~V}_{2} \mathrm{O}_{11}$ under monochromic light irradiation at $700 \mathrm{~nm}$ (Fig. 5). All of the photocatalysts evolved $\mathrm{H}_{2}$ and $\mathrm{O}_{2}$ from water at a molar ratio of $\sim 2$ to 1 , indicating that the overall water-splitting reaction proceeded. Notably, the $\mathrm{H}_{2}$ and $\mathrm{O}_{2}$ evolution rates initially decreased $(4 \mathrm{~h}$ photodeposition), then increased ( 20 and $35 \mathrm{~h}$ photodeposition), and then decreased again $(50 \mathrm{~h}$ photodeposition). The factors influencing these phenomena are discussed below.

To estimate the AQE values (Table 2), the total number of incident photons from the $700 \mathrm{~nm}$ LED light source was calculated from light intensities and the $\mathrm{H}_{2}$ evolution rates were calculated by a least squares method from the slopes of the plots in Figs. 5(a)-5(d). The obtained AQE values for $\mathrm{H}_{2}$ and $\mathrm{O}_{2}$ evolution were almost identical because the $\mathrm{H}_{2}$ and $\mathrm{O}_{2}$ evolution ratio was $\sim 2$ to 1 .

It should be noted that we can strictly compare the dependence of the water splitting efficiency on the amount of Pt cocatalyst because all the data shown by solid red and blue marks (i.e., evolved $\mathrm{H}_{2}$ and $\mathrm{O}_{2}$ ) in Figs. 5(a)-5(d) were obtained over $\mathrm{Pt} / \mathrm{ZnRh}_{2} \mathrm{O}_{4} / \mathrm{Ag} / \mathrm{Bi}_{4} \mathrm{~V}_{2} \mathrm{O}_{11}$ photocatalysts prepared from the same batch of $\mathrm{ZnRh}_{2} \mathrm{O}_{4} / \mathrm{Ag} /$ $\mathrm{Bi}_{4} \mathrm{~V}_{2} \mathrm{O}_{11}$. To confirm the reproducibility of the data, $\mathrm{ZnRh}_{2} \mathrm{O}_{4} / \mathrm{Ag} / \mathrm{Bi}_{4} \mathrm{~V}_{2} \mathrm{O}_{11}$ was prepared from the very
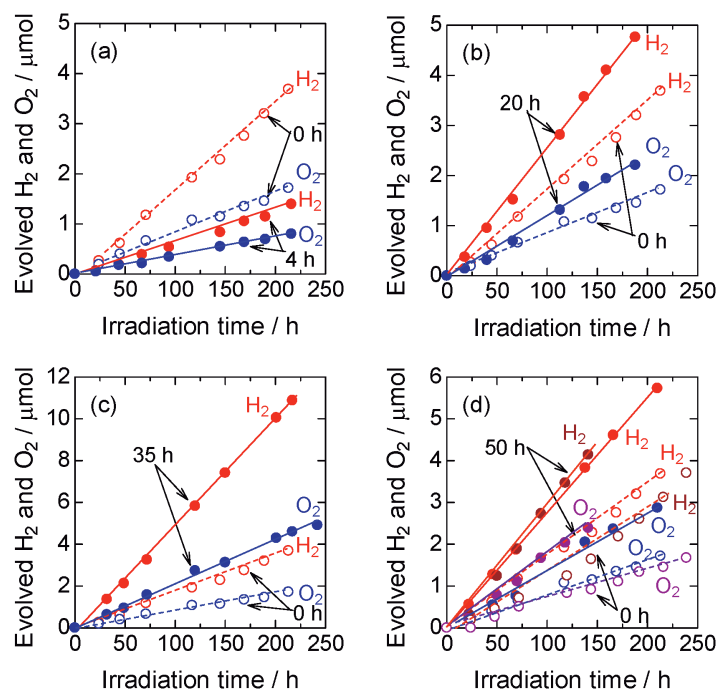

Fig. 5. Time courses of photocatalytic evolution of $\mathrm{H}_{2}$ and $\mathrm{O}_{2}$ from water over $\mathrm{Pt} / \mathrm{ZnRh}_{2} \mathrm{O}_{4} / \mathrm{Ag} / \mathrm{Bi}_{4} \mathrm{~V}_{2} \mathrm{O}_{11}$ prepared by $\mathrm{Pt}$ photodeposition of $4 \mathrm{~h}$ (a), $20 \mathrm{~h}$ (b), $35 \mathrm{~h}$ (c), and $50 \mathrm{~h}$ (d) under irradiation with $700 \mathrm{~nm}$ LED light (solid marks with solid lines). The evolution of $\mathrm{H}_{2}$ and $\mathrm{O}_{2}$ over bare $\mathrm{ZnRh}_{2} \mathrm{O}_{4} / \mathrm{Ag} / \mathrm{Bi}_{4} \mathrm{~V}_{2} \mathrm{O}_{11}$ is also shown for comparison (open marks with broken lines). In (d), confirmation of the data reproducibility shown by brown and purple marks.

Table 2. Light intensities, $\mathrm{H}_{2}$ generation rates, and $\mathrm{AQE}$ values for overall pure-water splitting over $\mathrm{ZnRh}_{2} \mathrm{O}_{4} / \mathrm{Ag} / \mathrm{Bi}_{4} \mathrm{~V}_{2} \mathrm{O}_{11}$ and $\mathrm{Pt} / \mathrm{ZnRh}_{2} \mathrm{O}_{4} / \mathrm{Ag} / \mathrm{Bi}_{4} \mathrm{~V}_{2} \mathrm{O}_{11}$

\begin{tabular}{cccc}
\hline $\begin{array}{c}\text { Photo-deposition time } \\
/ \mathrm{h}\end{array}$ & $\begin{array}{c}\text { Light intensity } \\
/ \mathrm{mW} \mathrm{cm}^{-2}\end{array}$ & $\begin{array}{c}\mathrm{H}_{2} \text { generation rate } \\
/ \mu \mathrm{molh}^{-1}\end{array}$ & $\begin{array}{c}\mathrm{AQE} \\
(\%)\end{array}$ \\
\hline 0 (bare) & 3.0 & $1.7 \times 10^{-2}$ & $1.5 \times 10^{-2}$ \\
4 & 3.2 & $6.1 \times 10^{-3}$ & $5.2 \times 10^{-3}$ \\
20 & 3.2 & $2.5 \times 10^{-2}$ & $2.2 \times 10^{-2}$ \\
35 & 3.5 & $5.0 \times 10^{-2}$ & $4.1 \times 10^{-2}$ \\
50 & 3.0 & $2.7 \times 10^{-2}$ & $2.5 \times 10^{-2}$ \\
\hline
\end{tabular}

beginning following the same procedure, and then $\mathrm{Pt}$ was photodeposited for $50 \mathrm{~h}$ under the same conditions. The $\mathrm{H}_{2}$ and $\mathrm{O}_{2}$ evolution vs. irradiation time from $\mathrm{ZnRh}_{2} \mathrm{O}_{4} / \mathrm{Ag} / \mathrm{Bi}_{4} \mathrm{~V}_{2} \mathrm{O}_{11}$ and $\mathrm{Pt} / \mathrm{ZnRh}_{2} \mathrm{O}_{4} / \mathrm{Ag} / \mathrm{Bi}_{4} \mathrm{~V}_{2} \mathrm{O}_{11}$ ( $50 \mathrm{~h}$ photodeposition of $\mathrm{Pt}$ ) under the same light conditions at a wavelength of $700 \mathrm{~nm}$ are included in Fig. 5(d). Both newly prepared photocatalysts evolved $\mathrm{H}_{2}$ and $\mathrm{O}_{2}$ from water at a molar ratio of $\sim 2$ to 1 , indicating that the overall water splitting reaction proceeded. The $\mathrm{H}_{2}$ and $\mathrm{O}_{2}$ evolution rates of the newly prepared $\mathrm{ZnRh}_{2} \mathrm{O}_{4} / \mathrm{Ag} /$ $\mathrm{Bi}_{4} \mathrm{~V}_{2} \mathrm{O}_{11}$ (brown and purple open marks, $\mathrm{H}_{2}$ generation rate $\left.=1.4 \times 10^{-2} \mu \mathrm{mol} \mathrm{h}^{-1}, \quad \mathrm{AQE}=1.2 \times 10^{-2} \%\right)$ and $\mathrm{Pt} / \mathrm{ZnRh}{ }_{2} \mathrm{O}_{4} / \mathrm{Ag} / \mathrm{Bi}_{4} \mathrm{~V}_{2} \mathrm{O}_{11}$ (brown and purple solid marks, $\mathrm{H}_{2}$ generation rate $=2.9 \times 10^{-2} \mu \mathrm{mol} \mathrm{h}^{-1}, \mathrm{AQE}=$ $\left.2.6 \times 10^{-2} \%\right)$ in Fig. 5(d) were almost identical within experimental errors to those for the original $\mathrm{ZnRh}_{2} \mathrm{O}_{4} / \mathrm{Ag} /$ $\mathrm{Bi}_{4} \mathrm{~V}_{2} \mathrm{O}_{11}$ (red and blue open marks) and $\mathrm{Pt} / \mathrm{ZnRh}_{2} \mathrm{O}_{4} /$ $\mathrm{Ag} / \mathrm{Bi}_{4} \mathrm{~V}_{2} \mathrm{O}_{11}$ (red and blue solid marks) in Fig. 5(d). So, we consider that the good reproducibility of the data was confirmed.

The most active photocatalyst for water splitting was prepared by $35 \mathrm{~h}$ of Pt photodeposition (Fig. 5, Tables 1 
and 2). This finding is plausible because the amount of $\mathrm{Pt}$ and proportion of $\mathrm{Pt}^{0}$ are the largest in $\mathrm{Pt} / \mathrm{ZnRh}_{2} \mathrm{O}_{4} / \mathrm{Ag} /$ $\mathrm{Bi}_{4} \mathrm{~V}_{2} \mathrm{O}_{11}$ (35 h photodeposition). It is reasonable to consider that the AQE tended to increase in the measurement range up to $0.17 \mathrm{wt} \% \mathrm{Pt}$ and that presence of $\mathrm{Pt}^{2+}$ or $\mathrm{Pt}^{3+}$ negatively affected the AQE because the photoexcited electrons in $\mathrm{ZnRh}_{2} \mathrm{O}_{4}$ are consumed by the reduction of $\mathrm{Pt}^{2+}$ or $\mathrm{Pt}^{3+}$. Thus, lowering the amount of $\mathrm{Pt}^{2+}$ and $\mathrm{Pt}^{3+}$ is expected to increase the AQE. Compared to the AQE of the photocatalyst prepared by the 35 -h photodeposition of $\mathrm{Pt}$, that of the 50-h photodeposited photocatalyst decreased due to the lower amount of Pt despite the similar portion of $\mathrm{Pt}^{0}$. In contrast, the $\mathrm{AQE}$ of 20 -h photodeposited photocatalyst decreased due to the lower portion of $\mathrm{Pt}^{0}$ and lower amount of Pt. However, in both cases, the AQE values remained higher than that of bare $\mathrm{ZnRh}_{2} \mathrm{O}_{4} / \mathrm{Ag}$ / $\mathrm{Bi}_{4} \mathrm{~V}_{2} \mathrm{O}_{11}$. The AQE values of 20 -h and 50 -h photodeposited photocatalysts became similar although the Pt amount and $\mathrm{Pt}^{0}$ portion of the 50 -h potodeposited photocatalyst were larger than those of the 20-h photocatalyst. This would be attributable to coarsening of Pt particles loaded at $50 \mathrm{~h}$. The photocatalyst prepared using 4-h photodeposition, which had the lowest AQE value, because of the lower amount of $\mathrm{Pt}$ and the lower proportion of $\mathrm{Pt}^{0}$. These findings demonstrate the importance of having the fine $\mathrm{Pt}$ cocatalyst loaded with $\mathrm{Pt}^{0}$. We cannot give a clear explanation why the AQE of 4-h photodeposited photocatalyst was lower than that of bare photocatalyst. In the two-photon excitation system like the present study, the activity should be the best, when the absorbed photon numbers by $\mathrm{ZnRh}_{2} \mathrm{O}_{4}$ and $\mathrm{Bi}_{4} \mathrm{~V}_{2} \mathrm{O}_{11}$ are identical, meaning that the numbers of photo-excited electrons in $\mathrm{ZnRh}_{2} \mathrm{O}_{4}$ and $\mathrm{Bi}_{4} \mathrm{~V}_{2} \mathrm{O}_{11}$ are identical. Here, we are considering that the cocatalyst $\mathrm{Pt}$ is deposited only on the surface of $\mathrm{ZnRh}_{2} \mathrm{O}_{4}$, then the shading effect by the deposited $\mathrm{Pt}$ should happen only to $\mathrm{ZnRh}_{2} \mathrm{O}_{4}$. So, the negative effect of the Pt loading in the two-photon excitation system is the deviation from the balance of the photon number contributing to the intended reactions by the two constituent photocatalysts, causing the decrease in the activity. It is well-known that the positive effect of Pt loading is the electron accumulation in $\mathrm{Pt}$, causing the effective electrons-and-holes separation, followed by the effective utilization of photo-excited electrons for reducing protons to produce $\mathrm{H}_{2}$. So, we are just speculating that the negative effect overwhelmed the positive effect in the 4-h photodeposited photocatalyst. Then, in the 20 -h photodeposited photocatalyst, the positive effect overwhelmed the negative effect with increasing the activity accompanied by increasing the amount of loaded Pt. Under these conditions, although the deposition of $\mathrm{Pt}$ did not always increase the $\mathrm{AQE}$, we can conclude that Pt functions as the cocatalyst for the overall water-splitting reaction.

\section{Conclusions}

The selective photodeposition of $\mathrm{Pt}$ as a cocatalyst onto $\mathrm{ZnRh}_{2} \mathrm{O}_{4}$ in $\mathrm{ZnRh}_{2} \mathrm{O}_{4} / \mathrm{Ag} / \mathrm{Bi}_{4} \mathrm{~V}_{2} \mathrm{O}_{11}$ enhanced the perfor- mance of water splitting when the amount of Pt exceeded $0.12 \mathrm{wt} \%$. The photodeposition of $\mathrm{Pt}$ in the form of $\mathrm{Pt}^{0}$ was essential to enhance the water-splitting activity. Following the Pt photodeposition procedure, photoirradiation at wavelengths up to $850 \mathrm{~nm}$ in the presence of $\mathrm{HCHO}$ and absence of $\mathrm{H}_{2} \mathrm{PtCl}_{6} \cdot 6 \mathrm{H}_{2} \mathrm{O}$ is expected to promote the formation of $\mathrm{Pt}^{0}$. Such investigations are now underway in our laboratory.

Acknowledgments This work was supported by JSPS KAKENHI (Grant-in-Aid for Scientific Research) Grant Number JP17H03126. We express gratitude to Mr. G. Newton for the careful reading of the manuscript.

\section{References}

1) A. Fujishima and K. Honda, Nature, 238, 37-38 (1972).

2) K. Maeda, K. Teramura, D. Lu, T. Takata, N. Saito, Y. Inoue and K. Domen, Nature, 440, 295 (2006).

3) Q. Wang, M. Nakabayashi, T. Hisatomi, S. Sun, S. Akiyama, Z. Wang, Z. Pan, X. Xiao, T. Watanabe, T. Yamada, N. Shibata, T. Takata and K. Domen, Nat. Mater., 18, 827-832 (2019).

4) K. Sayama, K. Mukasa, R. Abe, Y. Abe and H. Arakjawa, J. Photochem. Photobio. A, 148, 71-77 (2002).

5) R. Kobayashi, K. Kurihara, T. Takashima, B. Ohtani and H. Irie, J. Mater. Chem. A, 4, 3061-3067 (2016).

6) R. Kobayashi, T. Takashima, S. Tanigawa, S. Takeuchi, B. Ohtani and H. Irie, Phys. Chem. Chem. Phys., 18, 27693-28378 (2016).

7) K. Kamijyo, T. Takashima, M. Yoda, J. Osaki and H. Irie, Chem. Commun., 54, 7999-8002 (2018).

8) M. Yoda, T. Takashima, K. Akiyoshi, T. Torimoto and H. Irie, J. Chem. Phys., 153, 014701 (2020).

9) R. Kobayashi, S. Tanigawa, T. Takashima, B. Ohtani and H. Irie, J. Phys. Chem. C, 118, 22450-22456 (2014).

10) Q. Jia, A. Iwase and A. Kudo, Chem. Sci., 5, 1513-1519 (2014).

11) Z. Pan, T. Hisatomi, Q. Wang, S. Chen, M. Nakabayashi, N. Shibata, C. Pan, T. Takata, M. Katayama, T. Minegishi, A. Kudo and K. Domen, ACS Catal., 6, 7188-7196 (2016).

12) Z. Pan, G. Zhang and X. Wang, Angew. Chem. Int. Edit., 58, 7102-7106 (2019).

13) Q. Wang, T. Hisatomi, Q. Jia, H. Tokudome, M. Zhong, C. Wang, Z. Pan, T. Takata, M. Nakabayashi, N. Shibata, Y. Li, I. D. Sharp, A. Kudo, T. Yamada and K. Domen, Nat. Mater., 15, 611-615 (2016).

14) J. Osaki, M. Yoda, T. Takashima and H. Irie, RSC Adv., 9, 41913-41917 (2019).

15) H. Irie, M. Yoda, T. Takashima and J. Osaki, Appl. Catal. B-Environ., 284, 119744 (2020).

16) Y. Sasaki, H. Nemoto, K. Saito and A. Kudo, J. Phys. Chem. C, 113, 17536-17542 (2009).

17) G. B. Houflund, Z. F. Hazos and G. N. Salaita, Phys. Rev. B, 62, 11126-11133 (2000).

18) A. M. Ferraria, A. P. Carapeto and A. M. B. do Rego, Vacuum, 86, 1988-1991 (2012).

19) K. Kuribayashi and S. Kitamura, Thin Solid Films, 400, 160-164 (2001). 